\title{
Acrosternum Fieber (Heteroptera, Pentatomidae) in the Arabian Peninsula
}

\author{
Rauno E. Linnavuori \& Mousa M. Al-Safadi
}

Linnavuori, R. E. \& Al-Safadi, M. M. 1993: Acrosternum Fieber (Heteroptera, Pentatomidae) in the Arabian Peninsula. — Entomol. Fennica 4:235-239.

The species of the genus Acrosternum inhabiting the Arabian Peninsula are revised. New species: A. curticeps sp. n.

Rauno E. Linnavuori, Somersoja, SF-21220 Raisio, Finland

Mousa M. Al-Safadi, P.O. Box 392, Sana'a, Republic of Yemen

The Pentatomine genus Acrosternum Fieber consists of numerous species inhabiting the Ethiopian and Palearctic Regions. A revision of the Ethiopian species was published by Linnavuori (1972:416-431 and 1982:139-142) and of the Palearctic species by Wagner (1959:413-418). Notes of the distribution in Saudi Arabia and Yemen were given in Linnavuori 1986:65 and 1989. Among material collected during a recent field trip to Yemen a new species A. curiceps sp. $\mathrm{n}$. was found. Moreover, two species new for the Yemen fauna, A. arabicum Wagner and $A$. miliaris (Klug), were detected.

The collected material is the property of the American Museum of Natural History, but at present kept in the collection of REL.

Key to the species

1. Genae extending distinctly beyond tip of tylus (Fig. 1a). Caudoventral margin of pygofer (Fig. 1e-f) with a deep U-shaped median incision, delimited on each side by a sharply triangular lobe breviceps

- Genae extending to the level of apex of tylus. Pygofer different

2. Membrane of elytra with small round green spots. Upper surface strongly uneven owing to numerous small whitish callosities, forming transverse vermiculate ridges on pronotum, confluent spots on scutellum and sparse round spots on elytra. Male genitalia as in Figs. 2a-d, 3b-f miliaris

- Membrane of elytra hyaline, immaculate. Upper surface without conspicuous whitish callosities
3. Apex of scutellum broadly callose and white. Pygofer as in Fig. 2e ................................................. apicale

- Scutellum uniformly green ................................... 4

4. Large species, length 10-14 mm. Caudoventral margin of pygofer (Figs. 1g-h, 3a) only shallowly insinuated ........................................................... arabicum

- Smaller, length 9.0-11.5 mm. Pygofer different ..... 5

5. Head (Fig. 1d) short and broad, lateral margins of genae distinctly diverging caudad, apex of tylus narrowly visible. Caudoventral margin of pygofer (Fig. $4 \mathrm{a}-\mathrm{g}$ ) in ventral view shallowly insinuated ..curticeps

- Head (as in Fig. 1c) longer, lateral margins of genae in anterior part subparallel, then strongly recurved laterad in front of eyes. Caudoventral margin of pygofer (Fig. $2 \mathrm{f}-\mathrm{g}$ ) in ventral view deeply insinuated in middle ...... millierei

\section{A. breviceps (Jakovlev, 1890)}

Fig. 1a, e-f.

Material: Saudi Arabia: Al Hasa, 1 ex, 10.II22.IV.1978, Linnavuori. Also recorded from the Mecca District (China 1938:428).

Easily recognized by the shape of the head and the genitalia.

Distribution: Irano-Turanian, common in Iraq.

\section{A. arabicum Wagner, 1959}

Figs. 1b, g-h, 3a

Material: Saudi Arabia (localities listed in Linnavuori 1986:65) Yemen:, Shabwah, 5 exx, 23.IV.1992, Linnavuori. 


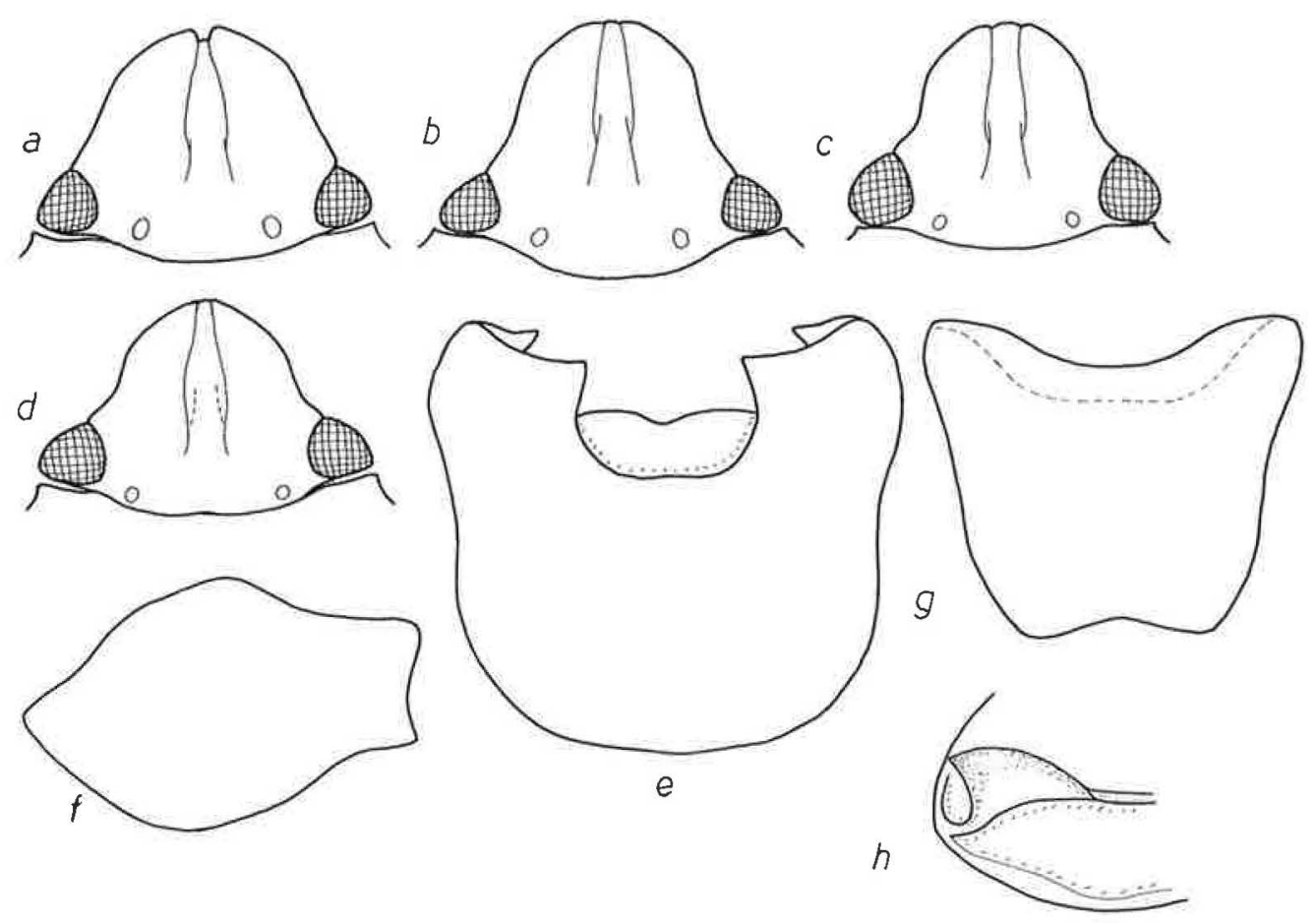

Fig. 1. Male head of Acrosternum breviceps (Jakovlev) a, A. arabicum Wagner b, A. miliaris (Klug) c, A. curticeps sp. n. d. - A. breviceps (Jakovlev). e-f: pygofer in ventral and lateral view. - A. arabicum Wagner. g: pygofer in ventral view; $\mathbf{h}$ : caudolateral angle of pygofer in dorsolateral view.

Larger than the related species, length 10-14 mm. Pygofer (Figs. 1g-h, 3a) distinctive: caudoventral margin shallowly insinuated, caudolateral angles with a broadly triangular sclerified lobe.

Biology: On shrubs in desert habitats.

Distribution: Eremian with eastern distribution, extending from the Arabian Peninsula to Iraq, Iran and Turkestan.

\section{A. apicale Linnavuori, 1975}

Fig. 2e

Types: Yemen: near Lahej, ơ holotype, 9-15.VII.1963, Linnavuori, in coll. Linnavuori (AMNH). Saudi Arabia: Asir, Sabya, 1 paratype, 1945, A. R. Waterston, in the National History Museum, London.

Acrosternum apicale Linnavuori 1975:101102.

A distinctive species, recognized by the whitish callose apical part of the scutellum and shape of the pygofer (Fig. 2e).

Biology: On shrubs in dune habitats.

Distribution: Endemic in SW Arabia.

A. miliaris (Klug, 1845)

Figs. 1c, 2a-d, 3b-f

Material: Yemen: the Hadhramaut, Al Mukalla, 2 exx, 7.IV.1992; Al Mukalla-Radoum, 1 ex, 7.IV.1992, Linnavuori.

Recognized by the strongly uneven upper surface with numerous whitish callosities, and the green-spotted elytral membranes. Male genitalia in Figs. 2a-d, 3b-f.

Biology: On shrubs in sandy habitats.

Distribution: North-Sudanese, extending from Senegal to Ethiopia. Not previously recorded from Arabia. 
Fig. 2. Acrosternum miliaris (Klug). a: pygofer in dorsal view; b: caudolateral angle of pygofer in dorsolateral view; c: style in lateral view; d: hypophysis of style in broad aspect. - A. apicale Linnavuori. e: pygofer in dorsal view. - A. millierei (Mulsant \& Rey). f-g: pygofer in dorsal and ventral view. - After Linnavuori 1972.

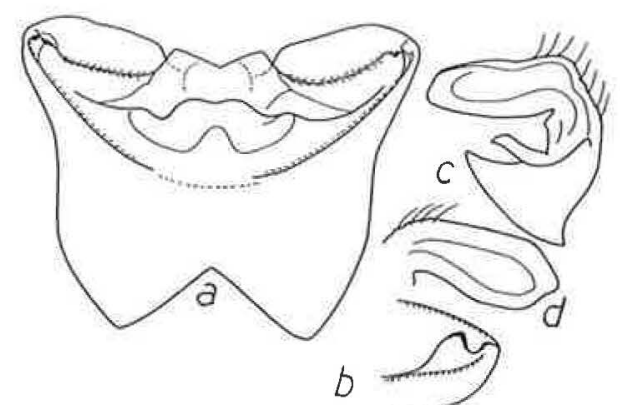

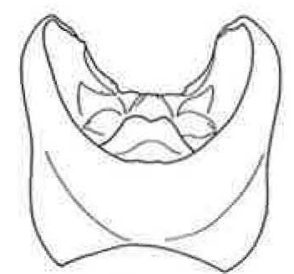

e
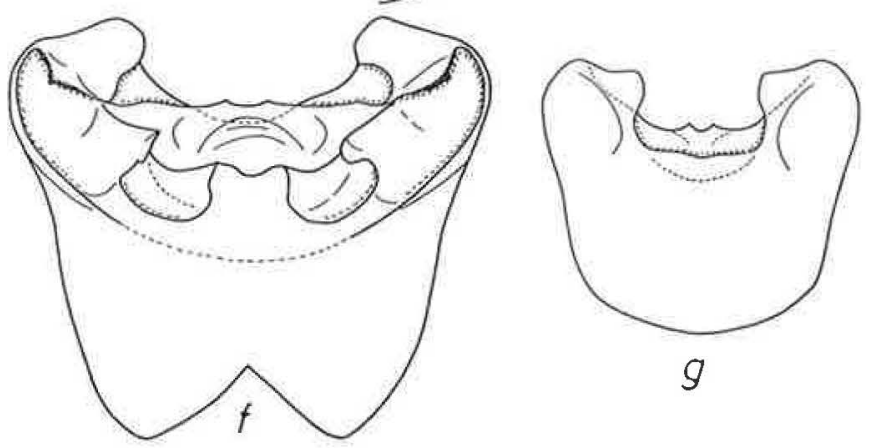

\section{A. curticeps sp. $\mathbf{n}$.}

Figs. 1d, 3g-i, 4a-h

Type: Yemen: Sana'a, Matnah, ơ holotype, 14.III.1992, Linnavuori, in coll. Linnavuori (AMNH).

Diagnosis: Closely related to A. miliaris, but readily distinguished by the short and broad head, short 2 nd antennal joint $(0.87-1.13 \times$ as long as 3rd in A. miliaris), absence of pale callosities on the upper surface, immaculate elytral membranes, and shape of the pygofer.

Length $9.5 \mathrm{~mm}$. Pale green with interspaces between punctures paler. Eyes grayish. 1st and 2nd antennal joints pale green, others ochraceous, segments 4 and 5 slightly embrowned. The very lateral margins of pronotum and basal thirds of costal margins of elytra pink, on under surface red. Membranes of elytra vitreous, immaculate. Lateroapical angles of paratergites black. Under surface and legs green, extreme lateral margins of venter pink. - General shape as in A. millierei. Body $1.7 \times$ as long as broad at base of pronotum. Head remarkably short and broad, $1.6 \times$ as broad as long, $0.45 \times$ as broad as basal width of pronotum; lateral margins of genae distinctly di- verging caudad already from apex, with only shallow insinuation in front of eyes, apex of tylus narrowly visible, puncturing of head very dense; eyes large, ocular index 2.5. Proportions between antennal segments 13:26:32:37:35, 2nd joint short, $0.8 \times$ as long as $3 \mathrm{rd}, 0.41 \times$ as long as diatone. Rostrum extending to hind coxae. Pronotum $2.8 \times$ as broad as long in middle, lateral margins strongly diverging caudad, humeral angles subacute; puncturing on disk (Fig. 3g) dense, \pm confluent, forming transverse vermiculate rows, interspaces between rows somewhat callose. Scutellum broadly triangular, nearly as long as broad, puncturing similar to that of pronotum. Puncturing on elytra slightly sparser, distinctly sparser than in A. millierei. Under surface densely punctate. - Male genitalia (Figs. $3 \mathrm{~h}-\mathrm{i}$, 4a-h): Caudoventral margin of pygofer shallowly insinuated, the dorsally convex lateral lobes on each side of the bilobate median part considerably narrower than in A. miliaris; caudolateral angles with two sclerified lobes, the outer one small, the inner one sharply triangular (broadly ligulate in A. miliaris). Anal tube and style as in Figs. $3 \mathrm{~h}-\mathrm{i}$ and $4 \mathrm{~h}$.

Biology: On shrubs in a hilly dry wadi. 


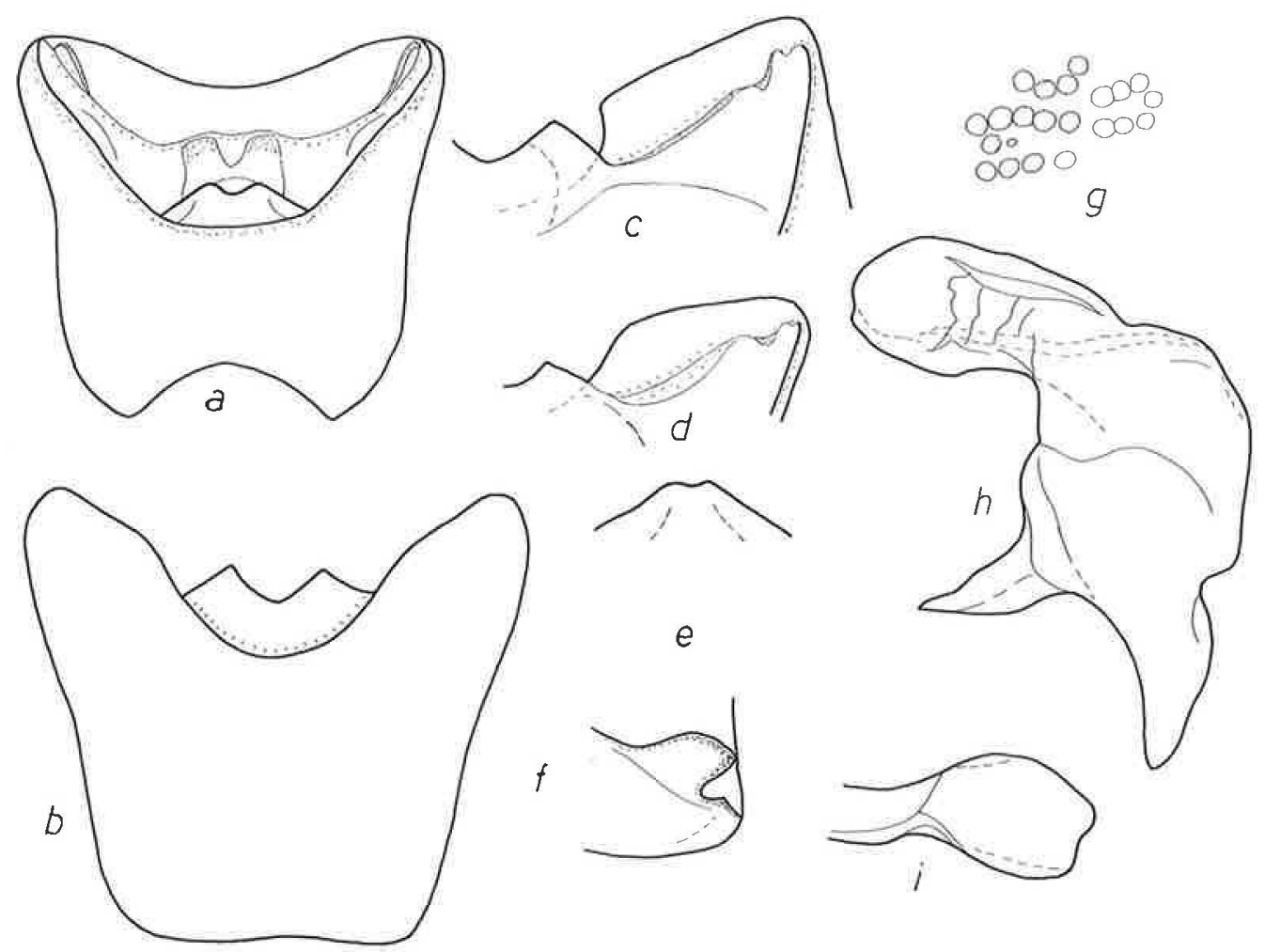

Fig. 3. Acrosternum arabicum Wagner. a: pygofer and anal tube in dorsal view. - A. miliaris (Klug). b: pygofer (ex from Al Mukalla) in ventral view; c-d: left side of caudolateral area of pygofer (exx from Tendelti in the Sudan and Al Mukalla, respectively) in dorsal view; e: dorsomedian process of pygofer; f: caudolateral angle of pygofer in dorsolateral view. - A. curticeps sp. n. g: puncturing on posterior lobe of pronotum; h: style (in slide mount) in lateral view; i: hypophysis of style (dry mount) in broad aspect.

\section{A. millierei (Mulsant \& Rey, 1866)}

Fig. $2 \mathrm{f}-\mathrm{g}$

Material: Previous records from Saudi Arabia and Yemen in Linnavuori 1986:65 and 1989:12. New records: Yemen: many exx from Sana'a, 25.II-4.III.1989, E. Heiss, VII-IX.1991, A. van Harten; Mahwit, Wadi Sara S of Al Mahwit, 17.III.1992, Wadi Surdud near Khamis Bani Said, 10.III.1992, Linnavuori; Dhamar, Hammam Ali near Ma'bar, 5.VIII.1991, A. van Harten, Wadi Siham, Al HajilaUban, 12.III.1992; Hudaydah, Al Miqlaf-Al Qanawis, 19.V.1992, Zabid, 20.V.1992; Ibb, Qatabah, 10.IV.1992; Ta'izz, Al Khawkah, 4.V.1992, 10 km S Al Khiyami, 22.III.1992, Al Matraq, 23.III.1992, Ta'izz, 22-23.III.1992; Abyan, Lawdar, 5-6.IV.1992; Hadhramaut, Al Mukalla, 7.IV.1992, Linnavuori.

A well-known species. Easily distinguished by the shape of the pygofer (Fig. $2 f-g$ ): caudoventral margin with a deep U-shaped median incision.

Biology: On shrubs such as Indigofera and herbaceous plants in fields and desert habitats.

Distribution: Holomediterranean with a wide range within the Sudanese subregion in Africa.

\section{Species excluded:}

\section{A. heegeri Fieber, 1861}

A Holomediterranean species which was undoubtedly incorrectly recorded from Arabia in Stichel 1961:763. The record apparently refers to $A$. arabicum. 


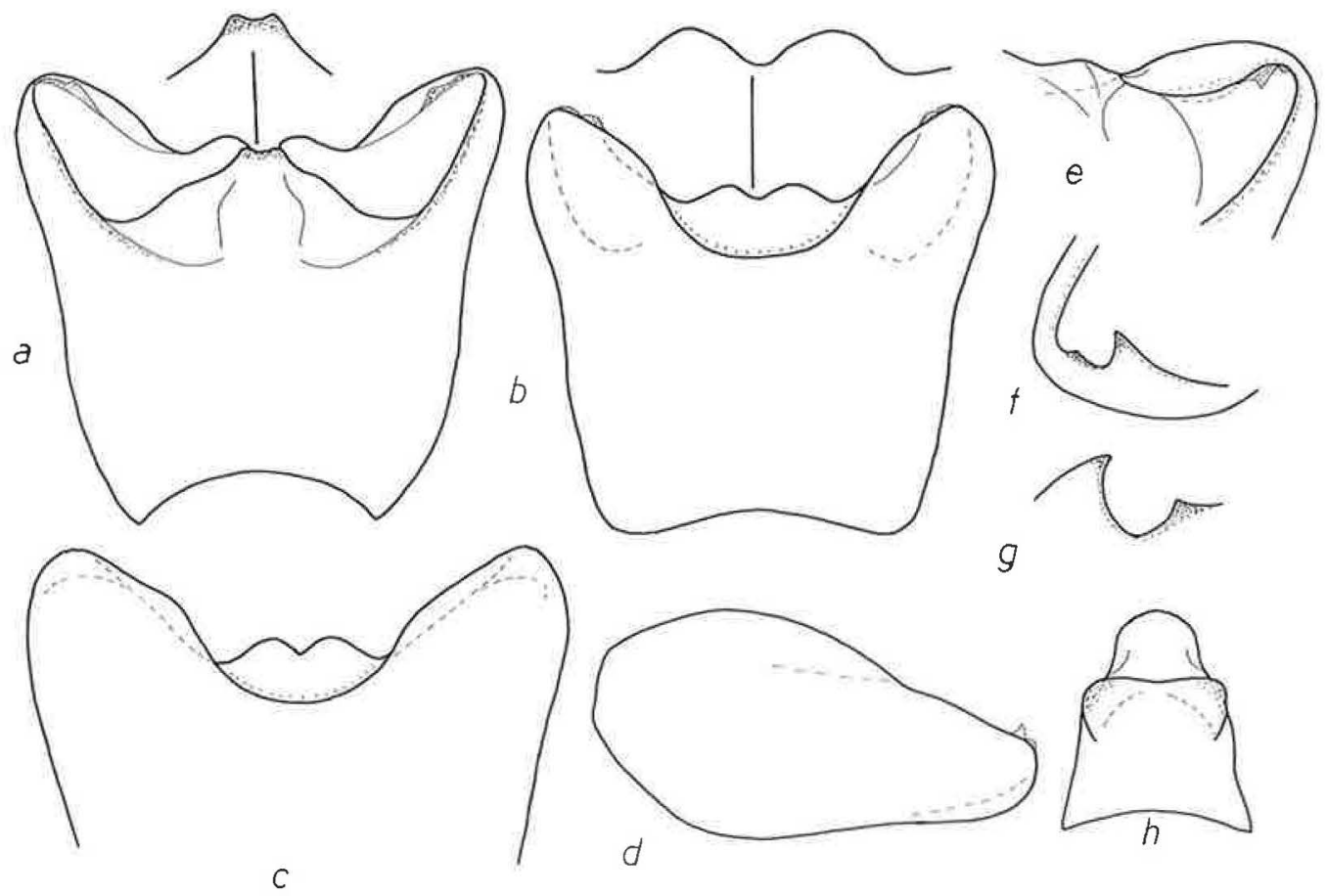

Fig. 4. Acrosternum curticeps sp. $\mathrm{n}$. a: pygofer in dorsal view; b-c: pygofer (b in glycerine, $\mathrm{c}$ in dry mount) in ventral view; d: pygofer in lateral view; e: left side of caudolateral area of pygofer (same view as in Fig. 3c-d) in dorsal view; g: caudolateral angle of left side of pygofer in dorsolateral view; g: caudolateral angle of right side of pygofer (the same view as in Fig. 3 j) in dorsolateral view: h: anal tube in dorsal view.

\section{References}

China, W. E. 1938: Hemiptera from Iraq, Iran, and Arabia. - Zool. Ser. Field Mus. Nat. Hist. Chicago 20:427437.

Linnavuori, R. E. 1972: Studies on African Pentatomidae. - Arq. Mus. Bocage 3(15):395-434.

- 1975: Hemiptera of the Sudan, with remarks on some species of the adjacent countries 5. Pentatomidae. Bol. Soc. Portuguesa Ci. Nat. 15:5-128.

- 1982: Pentatomidae and Acanthosomidae of Nigeria and the Ivory Coast, with remarks on species of the adjacent countries in West and Central Africa. - Acta Zool. Fennica 163:1-176.
- 1986: Heteroptera of Saudi Arabia. _ Fauna of Saudi Arabia 8:31-197.

- 1989: Heteroptera of Yemen and South Yemen. Acta Entomol. Fennica 54:1-40.

Stichel, W. 1961: Illustrierte Bestimmungstabellen der Wanzen. 2. Europa 4(24):737-768.

Wagner, E. 1959: Zur Systematik der Gattung Acrosternum Fieber (Hemiptera-Heteroptera: Pentatomidae). Bull. Soc. Entomol. Egypte 43:413-418.

Received 29.XII.1992 